Opioid Use Following Cesarean Delivery 1

\title{
Home Opioid Use Following Cesarean Delivery: How Many Opioid Tablets Should Obstetricians Prescribe?
}

\author{
Payton Schmidt, MD ${ }^{1}$, Mitchell B. Berger, MD, $\mathrm{PhD}^{1}$, Lori Day, MD¹, \\ Carolyn W. Swenson, MD ${ }^{1}$
}

${ }^{1}$ University of Michigan, Department of Obstetrics and Gynecology, $1500 \mathrm{E}$. Medical Center Dr., Ann Arbor, MI, 48109 USA

\footnotetext{
Corresponding Author:

Payton Schmidt, MD

L4100 Women's Hospital

1500 E Medical Center Dr., SPC 5276

Ann Arbor, MI 48109-5276

Phone (work): 734-763-6295

Fax: 734-647-9727

Email: payton@med.umich.edu
}

This is the author manuscript accepted for publication and has undergone full peer review but has not been through the copyediting, typesetting, pagination and proofreading process, which may lead to differences between this version and the Version of Record. Please cite this article as doi: $10.1111 /$ jog.13579

This article is protected by copyright. All rights reserved. 


\title{
Abstract: Home Opioid Use Following Cesarean Delivery: How Many Opioid Tablets Should Obstetricians Prescribe?
}

\begin{abstract}
Aim: To quantify home opioid use after cesarean delivery and identify factors associated with increased opioid use.
\end{abstract}

Methods: A convenience sample of women discharged by postoperative day two following a term cesarean delivery of a singleton fetus from May 2015-May 2016 were contacted two weeks postpartum and questioned regarding opioid use, pain control, and pain expectations.

Results: Among 141 women included in the analysis, the median number of opioid tablets used was 36 (interquartile range 16,45 ) and the median number prescribed was 60 (interquartile range 42, 65). Logistic regression identified operative time $\geq 59.5$ minutes and number of opioid tablets prescribed as two factors independently associated with opioid use in the top quartile.

Conclusions: In the first two weeks postpartum, $75 \%$ of women used 45 or fewer opioid tablets. Operative time over one hour and increased number of opioid tablets prescribed are factors associated with higher postpartum opioid use.

This article is protected by copyright. All rights reserved. 
Opioid Use Following Cesarean Delivery 3

Key Words: Analgesics, Opioid; Cesarean Section; Drug Prescriptions;

Postnatal Care; Practice Patterns, Physicians'

This article is protected by copyright. All rights reserved. 


\section{Introduction}

According to the Centers for Disease Control (CDC), prescription opioid overdose death rates more than tripled from 1999 to 2008 (1.4 vs 4.8 persons per 100,000 , respectively and 0.9 vs 3.7 female persons per 100,000 , respectively). ${ }^{1}$ To address the rising concern regarding the opioid abuse "epidemic," the CDC released an issue brief recommending that health care providers follow evidence-based guidelines for prescribing opioids. ${ }^{2}$

The most common indication for a patient's initial opioid prescription is surgery. ${ }^{3}$ This is likely related to the fact that opioid-based therapy regimens are the most commonly used treatment for postoperative pain. With cesarean deliveries (CD) being the most commonly performed surgery in the United States, ${ }^{4}$ it is important that obstetric providers prescribe opioids in a safe and effective way. However, as there is currently limited data ${ }^{5}$ quantifying home opioid needs following $C D$, we have limited evidence on which to base our opioid prescribing practices-much less to establish evidence-based guidelines.

A lack of guidelines regarding the average number of opioid tablets patients require following specific procedures or surgeries forces physicians to rely on their "best guess." This subjective approach has led to over-prescribing in many surgical specialties, as detailed in dermatologic, ${ }^{6}$ orthopedic, ${ }^{6}$ urologic, ${ }^{7}$ obstetric, $^{5,8}$ and gynecologic literature. ${ }^{9}$

Therefore, the primary aim of our study was to quantify the number of opioid tablets used by patients in the first two weeks following CD. A secondary 
aim was to identify factors available at the time of patient discharge that are independently associated with increased opioid use.

\section{Methods}

We conducted a retrospective study using a convenience sample of women undergoing a CD at the University of Michigan Health System between May 2015 and May 2016. The study does not violate the policies and/or procedures established by the journal and received exempt status from the University of Michigan Institutional Review Board (HUM00098254). A list of patients who met study criteria were obtained from our departmental database every two weeks during the study period. Women were included if they were age 18 years old or greater and status post CD for a term, singleton gestation. Our aim was to survey a low-risk population of postpartum women. Exclusion criteria included: less than 37 weeks gestational age at delivery, multifetal gestation, intrauterine fetal death/still birth, or any other complications requiring the infant and/or patient to still be hospitalized at two weeks postpartum. Women were also excluded if they were discharged after postoperative day two, which is customarily the day of discharge following an uncomplicated CD at our institution.

An attempt was made to contact women by phone on postoperative day 14 , and if unsuccessful, three total attempts were made through postoperative day 16 . Women were excluded if they were unable to be contacted after three 
attempts. A research assistant using a script conducted the interviews. Interview questions used the term "narcotic" rather than "opioid," as narcotics is deemed the term patients use and understand most. ${ }^{11}$ Consent was implied when women verbally agreed to participate. Women were given a verbal version of the Surgical Pain Scale, which assesses average pain on a scale of $0-10$ within the previous 24 hours during various levels of activity. ${ }^{10}$ Women were asked to specify the types of pain medications they were using and then count the number of narcotic tablets remaining from their original (or refilled) prescription. Women rated their overall pain control as poor, adequate, or good. They were also asked to rate their postoperative pain relative to what they expected their pain to be (much better than expected, better, about the same, worse, or much worse). Finally, they were asked about breastfeeding status. Chart review was then performed to obtain basic demographic, clinical, and peripartum data (including tobacco use, antepartum opioid use, and chronic pain-defined as a pre-pregnancy diagnosis of chronic pain, chronic back pain, migraines or chronic headaches, fibromyalgia, or temporomandibular joint pain). Data regarding the number of discharge opioids prescribed, as well as any opioid refills, were also obtained.

Our study group ultimately included women from two time periods over the course of the study: May through July 2015 and February through May 2016. The reason for these two "cohorts" was that while analyzing data from the initial groups, the average number of opioid tablets being prescribed at 
discharge had notably decreased. Therefore, we decided to collect data on a second group of women in 2016 to assess whether opioid prescribing practices had actually changed by virtue of our conducting the study.

Continuous data were tested for normality using histograms, as well as the Kolmogorov-Smirnov and Shapiro-Wilks tests. Bivariate analyses compared women whose opioid use was determined to be in the top quartile versus those in the bottom $75 \%$ in order to identify variables associated with increased opioid use. A similar comparison was done for women from the 2015 versus 2016 cohorts. Normally distributed data were analyzed using Student's t-test and nonparametric data were analyzed using Mann-Whitney $\mathrm{U}$ test. Categorical variables were analyzed using Chi-square or Fisher's exact tests where appropriate. Given the trend toward significance with infant weight, and our hypothesis that a higher infant weight may be a marker for pre-CD labor, require larger incisions, and/or have a more traumatic delivery, a receiver operator characteristic (ROC) curve was generated and the maximal Youden's index determined. The same was done for operative time. The optimal cut-off value for each was determined using Youden's index. ${ }^{12}$ The area under the ROC curve (AUC) was calculated for infant weight and operative time as well, and was used as an index of diagnostic accuracy. Variables significant in bivariate analyses were used in a logistic regression model to identify factors independently associated with women in the top quartile for opioid usage. 
Analyses were performed using IBM SPSS Statistics for Windows (Version 21.0. Armonk, MY: IBM Corp.).

\section{Results}

One hundred and forty-one women met inclusion and exclusion criteria. Of those, 99 were contacted between May and July 2015 and 42 were contacted from February to May 2016.

Overall, subjects were $32.0 \pm 4.9$ years old (mean \pm standard deviation) and had a BMI of $29.0 \pm 6.3 \mathrm{~kg} / \mathrm{m}^{2}$. One hundred and fourteen women were Caucasian (80.9\%), 12 were African-American (8.5\%), nine were Asian (6.4\%), and six were of another race $(4.2 \%)$. All of the study participants had low transverse incisions of both skin and uterus. Three women were discharged home on postpartum day one (two from the 2015 cohort and one from the 2016 cohort) and the remaining $97.9 \%(138 / 141)$ were discharged home on postpartum day two. Sixteen subjects had postoperative complications: nine had wound infection/dehiscence (56.3\%), three had preeclampsia (18.8\%), two had endometritis $(12.5 \%)$, one had mastitis $(6.3 \%)$, and one had pyelonephritis $(6.3 \%)$.

The median number of opioid tablets used in the first two weeks post-CD was 36 (interquartile range (IQR) 16, 45) and the median number prescribed was 60 (IQR 42, 65). The distribution of opioid-containing analgesic medications prescribed was as follows: $84.4 \%$ (119/141) oxycodone 5 mg/acetaminophen 
$325 \mathrm{mg} ; 6.4 \%$ (9/141) oxycodone $5 \mathrm{mg}$; and $1.4 \%(2 / 141)$ hydrocodone 5 mg/acetaminophen $325 \mathrm{mg}$. Overall, 94.3\% (133/141) of women reported using ibuprofen. While $54.6 \%$ (77/141) of women reported receiving "enough" opioid tablets at the time of discharge, $31.9 \%(45 / 141)$ thought they were prescribed "too much" and 12.8\% (18/141) stated their prescription was "not enough." Seven percent (10/141) of women received an opioid refill. Nineteen percent (27/141) were still using opioids and 63.8\% (90/138) were still using ibuprofen at two weeks postpartum.

Women who used more than 45 opioid tablets were determined to be in the top quartile and, with the exception of parity, had similar demographic characteristics as those who used $\leq 45$ tablets (Table 1 ). There were otherwise no statistically significant differences between the opioid use groups across demographic, peripartum, and postoperative variables. Ninety-eight percent of $C D$ involved residents and the level of resident did not differ significantly between groups.

Women in the top quartile used more than double the number of opioids compared to women in the bottom $75 \%$ (60 vs 25 tablets, $p<.001$ ). Table 1 shows a comparison of these two groups. Significant findings from this comparison showed that top quartile users were prescribed significantly more opioid tablets at discharge, were provided more opioid prescription refills, and reported continued use of opioid medications at two weeks postpartum, which was over three times the rate seen in women in the bottom $75 \%$. 
Overall, $97 \%$ of women reported pain control as good or adequate in both groups. Women in the top quartile reported higher pain scores at rest, during normal activities, and during the worst pain experienced on the day of the phone interview, as well as more frequently reporting their pain as "worse than expected." Table 2 shows a comparison of pain scores and pain expectations between women in the top quartile and those in the bottom $75 \%$ for opioid use.

The AUC for infant weight was 0.646 and the maximal Youden's index was 0.272 , corresponding to an optimal cut-off for infant weight of $\geq 3560$ grams. For operative time, the AUC was 0.607 and the maximal Youden's index was 0.35 , corresponding to an optimal cut-off of $\geq 59.5$ minutes. Using the cut-off values of infant weight of $\geq 3560$ grams and operative time $\geq 59.5$ minutes in bivariate analyses (see methods section for AUC and Youden's index calculations), women in the top quartile had a higher prevalence of infants weighing $\geq 3560 \mathrm{~g}(57.1 \%(20 / 35)$ vs $34.9 \%(37 / 106), \mathrm{p}=.03)$ and operative time $\geq 59.5$ minutes $(57.1 \%(20 / 35)$ vs $31.1 \%(33 / 106), p=.01)$. Table 3 shows the multivariable logistic regression performed using dichotomized infant weight and operative time, as well as variables significantly different from Table 1. Operative time $\geq 59.5$ minutes and number of opioid tablets prescribed at discharge remained independently associated with opioid use in the top quartile. Pearson's correlation between number of discharge opioids prescribed and number of opioids used was $0.45(p<.001)$. 
Data from the 99 women from 2015 and the 42 women from 2016 were then compared. Groups were similar for all demographic and perioperative variables except for parity $(1(1,2)$ [median $(I Q R)]$ vs $1(0,1)$, respectively, $p=.003$ ) and indication for CD (more women in 2016 underwent a scheduled CD (73.8\% (31/42) vs 53.5\% (53/99), $p=.03))$. Figure 1 shows the comparison of number of opioids prescribed and patient opioid use between the 2015 and 2016 cohorts. Women who underwent CD in 2016 received significantly fewer opioids at discharge and also used fewer opioids in the first two postpartum weeks. A smaller proportion of women from 2016 received an opioid prescription refill compared to those in 2015; however, this finding was not statistically significant $(2.4 \%$ (1/42) vs $9.1 \%(9 / 99), p=.16)$. Additionally, pain scores and satisfaction with pain control were similar between the groups (data not shown).

\section{Discussion}

In this study of women two weeks following a term CD and discharged home by postpartum day two, $75 \%$ used 45 or fewer opioid tablets. On average, patients were prescribed $40 \%$ more opioids than they used. Factors independently associated with being in the top quartile for opioid use included operative time $\geq 59.5$ minutes and increased number of discharge opioids prescribed. Over the course of the study, physicians decreased the number of discharge opioids prescribed and patients also used fewer. Variability in opioid 
prescribing practices and differences in consumption following CD highlight the need to better understand prescription patterns, utilization by patients, and the potential impact of these practices. Identifying risk factors for increased postpartum opioid requirements may help physicians prescribe opioids more accurately and therefore reduce surplus. The two factors we identified to be independently associated with postpartum opioid use in the top quartile were operative time $\geq 59.5$ minutes and number of opioids prescribed at discharge. We hypothesize that an increased operative time may be a marker of surgical difficulty or a result of additional planned or unplanned procedures. Surgical technique may also impact operative time as well, with shorter times associated with choosing not to close the peritoneum, ${ }^{13}$ blunt versus sharp abdominal entry, ${ }^{14}$ single versus double layer uterine closure, ${ }^{14}$ and no creation of a bladder flap. ${ }^{15}$ At our institution, surgical techniques used during CDs vary based on surgeon discretion and certain details may not be specified in the operative reports. Therefore, we were unable to determine the impact of variations in surgical technique on operative time in the current study.

Number of discharge opioid tablets prescribed was the other factor predictive of women in the top quartile for opioid use. This is concordant with findings by Bateman et al., who showed that being prescribed more opioids at discharge was associated with consuming more opioids, independent of pain severity at discharge or other patient characteristics. ${ }^{5}$ Because our study design precludes our ability to assess causality, we are unable to state with certainty 
why women who were prescribed more opioids used more-was it because more were available to use or because they were having more pain? Our finding, that women who underwent surgery in 2016 versus 2015 were prescribed significantly fewer discharge opioids and also used significantly fewer tablets, in conjunction with Bateman et al.'s findings, supports the first hypothesis.

These groups were otherwise similar in terms of demographics, perioperative variables, and patient-reported pain measures. Therefore, our results suggest that physician prescribing patterns may influence utilization of opioid pain medications by patients. Although chronic pain diagnoses and preoperative opioid use have been shown in prior studies to increase postoperative pain medication requirements, ${ }^{5,16,17}$ the absolute numbers of women with these characteristics in our study were low; consequently, we were likely underpowered to detect these differences.

Limitations of our study include the use of a relatively homogenous population collected via convenience sampling, which can be prone to selection bias and sampling errors. In an effort to minimize bias, we used a systemgenerated list of women who met our study criteria and attempted to call all women on the list. We limited our study to a relatively low-risk population discharged by postoperative day two, so our results may not be generalizable to high-risk pregnancies or patients discharged on postoperative day three or more. We also do not know how many opioid pills patients used following the 
first two postpartum weeks. Finally, our study was subject to "observed bias," as physicians began prescribing fewer discharge opioids after data on the initial 2015 cohort were collected. However, we feel that our study was actually strengthened by incorporation of data on the second cohort of women in 2016, as it reflects actual clinical practice.

This study also has several strengths. First, we present a simple yet effective method for quantifying home opioid use following surgery, and recall bias was limited because the phone interview was within two weeks of surgery. Second, we assessed patient pain using the Surgical Pain Scale, which in written form is a validated measurement tool. Third, to our knowledge this is the first study quantifying opioid use after hospital discharge following CD.

In summary, our findings suggest that a discharge prescription of 45 opioid tablets following a term CD for patients discharged on postoperative day one or two is acceptable for the majority of women. Operative time exceeding one hour is a risk factor for using a greater number of opioid tablets. Larger studies will be necessary to identify other patient-level modifiers that may impact postoperative opioid utilization. Ultimately, these data could serve as a reference for developing evidence-based guidelines for opioid prescribing following cesarean delivery. 
Acknowledgments: Investigator support for Carolyn Weaver Swenson was provided by the National Institute of Child Health and Human Development WRHR Career Development Award K12 HD065257.

Disclosure: No author has any potential conflict of interest. 


\section{References}

1. Centers for Disease Control and Prevention (CDC). Vital signs: overdoses of prescription opioid pain relievers---United States, 1999-2008. MMWR Morb Mortal Wkly Rep 2011;60(43): 1487-1492.

2. Centers for Disease Control and Prevention. Policy Impact: Prescription Painkiller Overdoses. 2011 [cited 1 Jan 2017]. Available from http://www.cdc.gov/drugoverdose/pdf/policyimpact-prescriptionpainkilleroda.pdf.

3. Hooten WM, St Sauver JL, McGree ME, Jacobson DJ, Warner DO. Incidence and Risk Factors for Progression From Short-term to Episodic or Long-term Opioid Prescribing: A Population-Based Study. Mayo Clin Proc 2015;90(7): 850-856.

4. Centers for Disease Control and Prevention. Number of all-listed procedures for discharges from short-stay hospitals, by procedure category and age: United States, 2010. 2010 [cited 1 July 2016]. Available from https://www.cdc.gov/nchs/data/nhds/4procedures/2010pro4_numberproced ureage.pdf.

5. Bateman BT, Cole NM, Maeda A, Burns SM, Houle TT, Huybrechts KF, Clancy CR, Hopp SB, Ecker JL, Ende H, Grewe K, Raposo Corradini B, Schoenfeld RE, Sankar K, Day LJ, Harris L, Booth JL, Flood P, Bauer ME, 
Tsen LC, Landau R, Leffert LR. Patterns of Opioid Prescription and Use After Cesarean Delivery. Obstet Gynecol. 2017 Jul;130(1):29-35.

6. Macintyre PE, Huxtable CA, Flint SL, Dobbin MD. Costs and consequences: a review of discharge opioid prescribing for ongoing management of acute pain. Anaesth Intensive Care 2014;42(5): 558-574.

7. Bates C, Laciak R, Southwick A, Bishoff J. Overprescription of postoperative opioids: a look at postoperative pain medication delivery, consumption and disposal in urological practice. J Urol 2011;185(2): 551555.

8. Bartels K, Mayes LM, Dingmann C, Bullard KJ, Hopfer CJ, Binswanger IA. Opioid Use and Storage Patterns by Patients after Hospital Discharge following Surgery. PLoS One 2016;11(1): e0147972.

9. Swenson CW, Kelley AS, Fenner DE, Berger MB. Outpatient Opioid Use After Minimally Invasive Urogynecologic Surgery. Female Pelvic Med Reconstr Surg 2016;22(5): 377-381.

10. McCarthy M,Jr, Chang $\mathrm{CH}$, Pickard AS, et al. Visual analog scales for assessing surgical pain. J Am Coll Surg 2005;201(2):245-252.

11. Mangione MP, Crowley-Matoka M. Improving Pain Management Communication: How Patients Understand the Terms "Opioid" and “Narcotic." J Gen Intern Med 2008;23(9): 1336-1338.

12. Youden WJ. Index for rating diagnostic tests. Cancer 1950;3(1): 32-35. 
13. CORONIS Collaborative Group, Abalos E, Addo V, et al. Caesarean section surgical techniques (CORONIS): a fractional, factorial, unmasked, randomised controlled trial. Lancet 2013;382(9888): 234-248.

14. Ferrari AG, Frigerio LG, Candotti G, et al. Can Joel-Cohen incision and single layer reconstruction reduce cesarean section morbidity? Int $J$ Gynaecol Obstet 2001;72(2): 135-143.

15. Hohlagschwandtner M, Ruecklinger E, Husslein P, Joura EA. Is the formation of a bladder flap at cesarean necessary? A randomized trial. Obstet Gynecol 2001;98(6): 1089-1092.

16. Rapp SE, Ready LB, Nessly ML. Acute pain management in patients with prior opioid consumption: a case-controlled retrospective review. Pain 1995;61(2): 195-201.

17. Zarling BJ, Yokhana SS, Herzog DT, Markel DC. Preoperative and Postoperative Opiate Use by the Arthroplasty Patient. J Arthroplasty 2016;31(10): 2081-2084. 
Opioid Use Following Cesarean Delivery 19

\section{Figure Legend}

Figure 1. Changes in Number of Discharge Opioid Tablets Prescribed Following Cesarean Delivery and Patient Opioid Use Over the Study Period

${ }^{*}$ Comparison of number of opioid tablets prescribed between 2015 and 2016.

${ }^{* *}$ Comparison of number of opioid tablets used by patients between 2015 and 2016. 
Table 1. Demographics, perioperative variables, and two-week postoperative opioid use for women who underwent cesarean delivery

\begin{tabular}{|c|c|c|c|}
\hline \multirow[t]{2}{*}{$\begin{array}{l}\text { Demographics and Perioperative } \\
\text { Variables }\end{array}$} & \multicolumn{3}{|c|}{$\begin{array}{l}\text { Number of Opioid Tablets Used } \\
\qquad(\mathrm{N}=141)\end{array}$} \\
\hline & $\begin{array}{c}\leq 45 \\
(N=106)\end{array}$ & $\begin{array}{c}>45 \\
(\mathrm{~N}=35)\end{array}$ & $P$ value \\
\hline Age, years & $31.9 \pm 4.7$ & $32.2 \pm 5.6$ & .70 \\
\hline Parity & $1(0,2)$ & $1(0,1)$ & .04 \\
\hline BMI, $\mathrm{kg} / \mathrm{m}^{2}$ & $28.8 \pm 6.5$ & $29.7 \pm 5.3$ & .48 \\
\hline Race/Ethnicity & & & 0.73 \\
\hline Caucasian & $83(78.3)$ & $31(88.6)$ & -- \\
\hline Asian & $8(7.5)$ & $1(2.9)$ & -- \\
\hline African American & $9.4(10)$ & $5.7(2)$ & -- \\
\hline Hispanic & $2(1.9)$ & $0(0)$ & -- \\
\hline Other/Unknown & $3(2.8)$ & $1(2.9)$ & \\
\hline Tobacco User & $9(8.5)$ & $5.7(2)$ & .60 \\
\hline Cesarean Delivery $^{\ddagger}$ & & & .59 \\
\hline Primary & $45(42.5)$ & $19(54.3)$ & -- \\
\hline Repeat & $61(57.5)$ & $16(45.7)$ & -- \\
\hline Chronic Pain Diagnosis ${ }^{\S}$ & $7(6.6)$ & $3(8.6)$ & .71 \\
\hline Antepartum Opioid Use & $2(1.9)$ & $0(0.0)$ & $>.99$ \\
\hline Gestational Age, weeks & $39.3(39.0,39.9)$ & $39.1(38.6,40.3)$ & .63 \\
\hline Infant Weight, grams & $3495.70 \pm 487.5$ & $3683.4 \pm 538.6$ & .06 \\
\hline Indication for Cesarean Delivery & & & .11 \\
\hline Scheduled/planned & $67(63.2)$ & $17(48.6)$ & -- \\
\hline Arrest of descent & $18(17.0)$ & $5(14.3)$ & -- \\
\hline
\end{tabular}


Arrest of dilation

Fetal indication

Labored prior to Cesarean Delivery

Length of active second stage, minutes

Operative Time, minutes

Skin Closure

Staples

Suture

Estimated Blood Loss, $\mathrm{mL}$

Opioids Tablets Prescribed at Discharge

\section{At Two Weeks Postpartum}

Opioids Tablets Used

Received a Opioid Refill

Still Using Opioids

Still Using Ibuprofen

Breastfeeding

Postoperative complication
$602.6 \pm 337.0$

$56.1 \pm 17.9$

$11(10.4)$

95 (89.6)

$800(800,1,000)$

$50(40,60)$

$25(12,39)$

$3(2.8)$

$13(12.3)$

$60(56.6)$

$88(83.0)$

$13(12.3)$
$7(20.0)$

$6(17.1)$

$11(31.4)$

.36

$681.8 \pm 339.7$

.64

$60.7 \pm 20.0$

.20

.41

$2(5.7)$

33 (94.3)

$850(800,1,000)$

.15

$60(60,70)$

$<.001$

$<.001$

.001

7 (20.0)

$<.001$

$14(40.0)$

.003

$30(85.7)$

$29(82.9)$

.98

$3(8.6)$

.76 
Table 2. Pain scores and expectations for women who underwent a cesarean delivery

\begin{tabular}{|c|c|c|c|}
\hline \multirow[b]{2}{*}{ Pain Scores and Expectations } & \multicolumn{3}{|c|}{ Number of Opioid Tablets Used ${ }^{\dagger}$} \\
\hline & $\begin{array}{c}\leq 45 \\
(N=106)\end{array}$ & $\begin{array}{c}>45 \\
(N=35)\end{array}$ & $\mathrm{P}$ value \\
\hline \multicolumn{4}{|c|}{$\begin{array}{l}\text { Surgical Pain Scale Scores Two Weeks Postoperatively } \\
\text { ( } 0=\text { no pain, } 10=\text { worst pain imaginable) }\end{array}$} \\
\hline $\begin{array}{l}\text { What was the average amount } \\
\text { of pain you had when you were } \\
\text { at rest? }\end{array}$ & $0(0,2.0)$ & $1.5(1,3)$ & .018 \\
\hline $\begin{array}{l}\text { How much pain did you have } \\
\text { during your normal activities (for } \\
\text { example walking, climbing stairs, } \\
\text { driving a car, getting up from a } \\
\text { chair)? }\end{array}$ & $1(1,3)$ & $3(1,5)$ & .002 \\
\hline $\begin{array}{l}\text { How much pain did you have } \\
\text { when you were exercising, doing } \\
\text { strenuous work, or lifting objects } \\
\text { you used to be able to lift } \\
\text { comfortably? }\end{array}$ & $\begin{array}{l}2(1,3) \\
(\mathrm{N}=59)\end{array}$ & $\begin{array}{l}2(2,4.5) \\
(\mathrm{N}=14)\end{array}$ & .395 \\
\hline $\begin{array}{l}\text { How unpleasant or disturbing } \\
\text { was the worst pain that you had } \\
\text { today? }\end{array}$ & $1(0,3)$ & $3.5(1,5.25)$ & .002 \\
\hline \multicolumn{3}{|c|}{ Overall Rating of Postpartum Pain Control Two Weeks } & 11 \\
\hline \multicolumn{3}{|l|}{ Postoperatively } & .11 \\
\hline Poor & $3(2.8)$ & $1(2.9)$ & \\
\hline Adequate & $24(22.6)$ & $13(37.1)$ & \\
\hline Good & $79(74.5)$ & $21(60.0)$ & \\
\hline \multicolumn{3}{|c|}{ Postpartum Pain versus Expectation Two Weeks Postoperatively } & .02 \\
\hline Much Worse Than Expected & $3(2.8)$ & $0(0.0)$ & \\
\hline Worse Than Expected & $13(12.3)$ & $10(28.6)$ & \\
\hline About What Expected & $41(38.7)$ & $13(37.1)$ & \\
\hline Better Than Expected & $23(21.7)$ & $12(34.3)$ & \\
\hline Much Better Than Expected & $26(24.5)$ & $0(0.0)$ & \\
\hline
\end{tabular}


Opioid Use Following Cesarean Delivery 23

${ }^{\dagger}$ Data presented as median (IQR) or N (\%). P values calculated using Chi-Square, Fisher's exact test, or Mann-Whitney U.

This article is protected by copyright. All rights reserved. 
Table 3. Factors available at discharge and associated with women in the top quartile for opioid use during the first two weeks following cesarean delivery ${ }^{\dagger}$

\begin{tabular}{lcccccc}
\hline \multicolumn{1}{c}{ Variable } & $\begin{array}{c}\text { Crude } \\
\text { Odds } \\
\text { Ratio }\end{array}$ & $\begin{array}{c}\text { Adjusted } \\
\text { Odds } \\
\text { Ratio }\end{array}$ & 95\% C.I. & $\begin{array}{c}\text { Regression } \\
\text { Coefficient }\end{array}$ & $\begin{array}{c}\text { Standard } \\
\text { Error }\end{array}$ & $\begin{array}{c}\text { P } \\
\text { value }\end{array}$ \\
\hline Constant & -- & 0.01 & -- & -4.96 & 1.13 & $<.001$ \\
Parity & 0.58 & 0.63 & $0.37-1.08$ & -0.46 & 0.27 & .09 \\
$\begin{array}{l}\text { Infant Weight } \geq 3560 \\
\text { grams }\end{array}$ & 2.49 & 2.27 & $0.95-5.43$ & 0.82 & 0.44 & .06 \\
$\begin{array}{l}\text { Operative Time } \\
\geq 59.5 \text { minutes }\end{array}$ & 2.95 & 2.70 & $1.12-6.53$ & 0.99 & 0.45 & .03 \\
$\begin{array}{l}\text { Number of Opioid } \\
\begin{array}{l}\text { Tablets Prescribed } \\
\text { at Discharge }\end{array}\end{array}$ & 1.07 & 1.06 & $1.03-1.10$ & 0.06 & 0.02 & $<.001$ \\
$\begin{array}{l}\text { F Logistic regression performed including variables significant in bivariate analyses for women in the top } \\
\text { quartile of postpartum opioid use. }\end{array}$
\end{tabular}

This article is protected by copyright. All rights reserved. 
Figure 1. Changes in Number of Discharge Opioid Tablets Prescribed Following Cesarean Delivery and Patient Opioid Use Over the Study Period

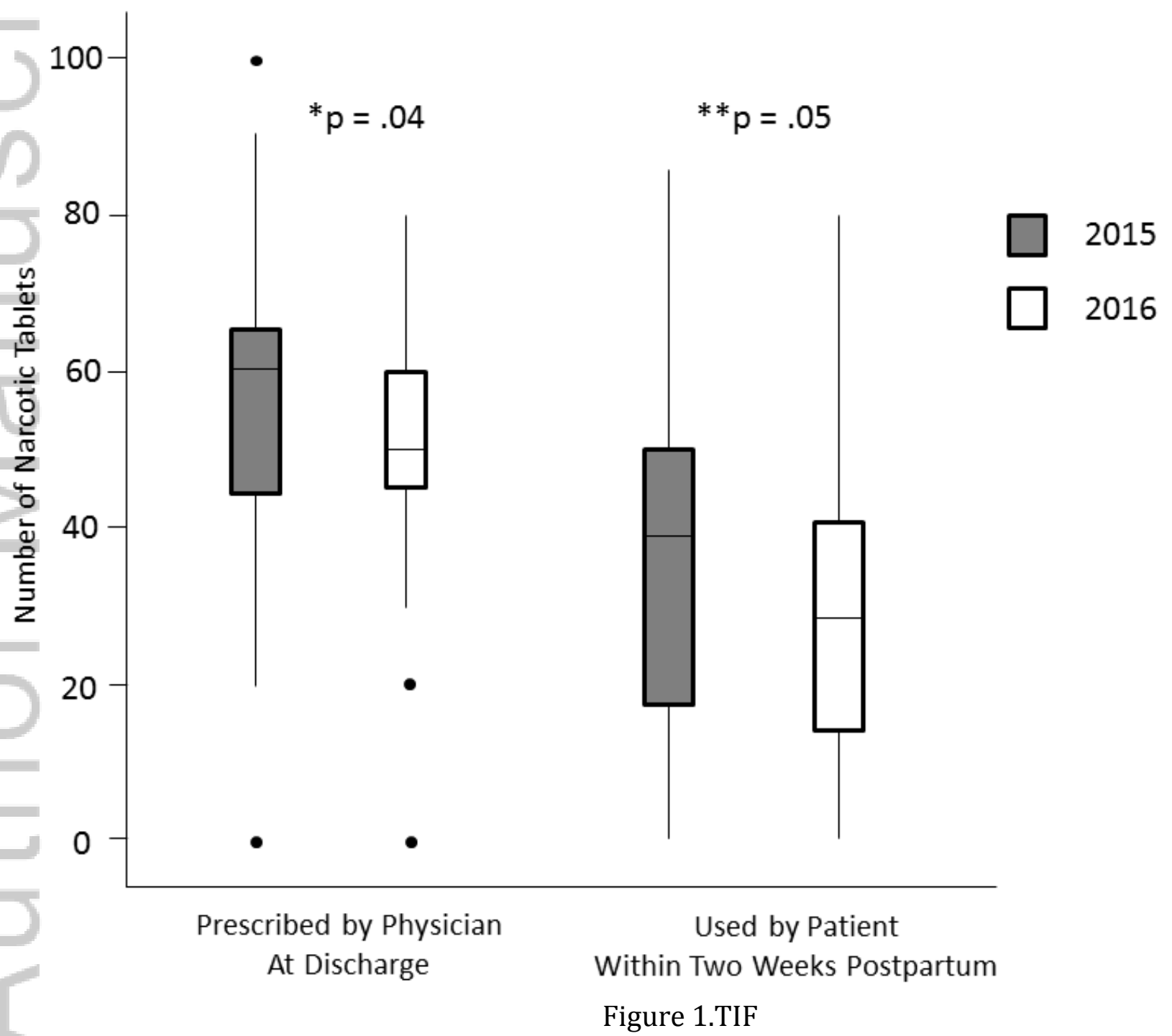

This article is protected by copyright. All rights reserved. 